einstein

Official Publication of the Instituto Israelita

de Ensino e Pesquisa Albert Einstein

ISSN: 1679-4508 | e-ISSN: 2317-6385

\title{
Analysis of electroencephalography brain rhythms in the reading process
}

\section{Análise dos ritmos cerebrais de eletroencefalografia no processo de leitura}

Camila Davi Ramos', Izabella Nonato Oliveira Lima', Amanda Luiza Rodrigues', Kaliny Alice Carvalho de Oliveira Magalhães', Aurélia Aparecida de Araújo Rodrigues', João-Batista Destro-Filho ${ }^{1}$

${ }^{1}$ Universidade Federal de Uberlândia, Uberlândia, MG, Brazil.

DOI: 10.31744/einstein_journal/2020A05442

\section{ABSTRACT}

Objective: To verify if, by three distinct quantifiers, the measured electroencephalographic signal at rest is different from the signal measured during a word reading situation, especially considering the faster rhythms, gamma and high-gamma, as it occurs in clinical rhythms (delta to beta). Methods: A total of 96 electroencephalographic signals measured from neurologically healthy volunteers were evaluated at two moments: resting and word reading. Each signal segment was measured by three quantifiers that separately assess normalized power, percent power, and right and left hemisphere coherence. The Mann-Whitney test was used to compare the results of the quantifiers in each brain range. Results: The gamma and high-gamma rhythms presented a more distinct behavior when comparing the analyzed moments (resting and reading) than the clinical rhythms. Conclusion: This finding contributes to the scarce literature on faster rhythms, which can contain information that is normally disregarded in neurological clinical practice.

Keywords: Electroencephalography; Reading; Gamma rhythm; Delta rhythm; Beta rhythm

How to cite this article:

Ramos CD, Lima IN, Rodrigues AL, Magalhães KA, Rodrigues AA, Destro-Filho JB. Analysis of electroencephalography brain rhythms in the reading process. einstein (São Paulo). 2020;18:eA05442. http://dx.doi.org/10.31744/ einstein journal/2020A05442

Corresponding author:

Camila Davi Ramos

Avenida João Naves de Ávila, 2.121

Santa Mônica

Zip code: 38400-902 - Uberlândia, MG, Brazil

Phone: (55 34) 99670-2051

E-mail: camiladavi.r@gmail.com

Received on:

Oct 14, 2019

Accepted on:

Mar 6, 2020

Conflict of interest:

none.

Copyright 2020

(c) BY

This content is licensed

under a Creative Commons

Attribution 4.0 International License.

\section{RESUMO}

Objetivo: Verificar se, por meio de três quantificadores distintos, o sinal eletroencefalográfico medido em repouso é diferente do sinal medido durante o processo de leitura, especialmente considerando os ritmos rápidos, gama e supergama, assim como ocorre nos ritmos clínicos delta a beta. Métodos: Foram avaliados 96 sinais eletroencefalográficos medidos em voluntários neurologicamente saudáveis, em dois momentos: repouso e leitura de palavras. Cada trecho do sinal foi mensurado por três quantificadores que medem, de maneira isolada, a potência normalizada e a potência percentual, bem como a coerência entre os hemisférios direito e esquerdo. 0 teste estatístico de Mann-Whitney foi usado para comparar os resultados dos quantificadores em cada faixa cerebral. Resultados: 0s ritmos gama e supergama apresentaram comportamento mais distinto entre os momentos analisados (repouso e leitura) que os ritmos clinicamente analisados. Conclusão: Esse achado contribui com a escassa literatura segundo a qual os ritmos rápidos podem conter informações que normalmente são descartadas na neurologia clínica.

Descritores: Eletroencefalografia; Leitura; Ritmo gama; Ritmo delta; Ritmo beta

\section{INTRODUCTION}

Reading improves the storage of information in the human brain, and requires a combination of skills and continuous study to enhance knowledge by 
learning of new words. ${ }^{(1)}$ Multiple brain systems must interact cooperatively for a word to be recognized and a homogeneous interpretation of the visual input to occur. (2) Research indicates that several brain regions are triggered during reading. ${ }^{(3)}$ However, using neuroimaging, it has been shown that an area in the occipitotemporal cortex is activated in fluent readers. ${ }^{(4)}$ This region, located in the fusiform gyrus, has been termed the visual word form area. ${ }^{(5)}$ Studies showed the activation of this region is evoked by written words, but not by spoken words. ${ }^{(5)}$ Besides improving previously acquired knowledge, reading also improves auditory and visual perception, ${ }^{(6)}$ and is a particular form of human evolution.

During a word reading situation, the electrical activity of the brain changes, and these changes can be captured in electroencephalogram (EEG) recordings. The transmission of brain information occurs via electrical activity, and the EEG records this activity, which is detected by electrodes placed on the scalp, ${ }^{(7,8)}$ according to the following neuroanatomical locations: frontal $(\mathrm{F})$, central $(\mathrm{C})$, parietal $(\mathrm{P})$, temporal $(\mathrm{T})$, occipital $(\mathrm{O})$. Odd numbered electrodes represent the left cerebral hemisphere, and even numbered electrodes represent the right hemisphere. ${ }^{(9)}$

The EEG spectral analysis is performed in the EEG frequency bands, which have well-defined limits, ${ }^{(9,10)}$ namely: delta (ranging from 0.5 to $3.5 \mathrm{~Hz}$ ), theta (from 3.5 to $7.5 \mathrm{~Hz}$ ), alpha (ranging from 7.5 to $12.5 \mathrm{~Hz}$ ), beta (from 12.5 to $30 \mathrm{~Hz}$ ), gamma (from 30 to $80 \mathrm{~Hz}$ ), and high-gamma (above $80 \mathrm{~Hz}) .{ }^{(10,11)}$ The literature reports that the gamma and high-gamma rhythms are related to cognitive tasks involving perception, attention and memory. ${ }^{(12,13)}$ However, as far as the authors are aware, no study analyzed the reading process per se. All previous studies analyzed reading associated with word comprehension, text interpretation, and visual stimulation. In addition, few articles studied the reading process in frequency bands above $40 \mathrm{~Hz},{ }^{(1,4,9,14)}$ particularly in the context of Brazilian or Latin American individuals, assessing the degree of quantitative EEG changes that occur between resting and reading states, which is extremely important for a correct calibration of a brain-machine interface.

\section{OBJECTIVE}

To measure, by quantitative processing, the electroencephalographic signals of neurologically healthy volunteers during a word reading situation and in a resting situation, and to verify if the gamma and high-gamma rhythms contribute significantly to the differentiation between the reading and the resting states, demonstrating possible changes in brain activity caused by these rhythms in these two situations.

\section{॥ METHODS}

This study was carried out in the first semester of 2019 and addressed the following topics in its methodological process: data collection; pre-processing; quantification of the brain signal; and statistical analysis.

\section{Data collection}

We analyzed EEG signals considered neurologically normal, collected from an EEG database and recorded from healthy volunteers, between the years 2016 and 2018. ${ }^{(15)}$ Authorization by the Research Ethics Committee of the Universidade Federal de Uberlândia (UFU) was released under CAAE: 54781615.6.0000.5152, with approval number 1.715.960, allowing the collection and use/processing of these data. From this database, 96 EEG records were used (49 of the records were from male volunteers). The mean age of the volunteers was $24 \pm 7.5$ years.

We used a 20-channel EEG equipment, with a high-pass filter with a cut-off frequency of $1 \mathrm{~Hz}$, a $100 \mathrm{~Hz}$ low-pass filter, and a filter that rejected the range between 58 and $62 \mathrm{~Hz}$. The sampling frequency and impedance values set for the device were $1 \mathrm{kHz}$ and $1 \mathrm{~K} \Omega$, respectively. All records were collected following the international 10-20 collection system. The protocol recorded two events: event 1, termed no stimulus (NS) event, and event 2, in which the volunteer read ten words sequentially, termed word reading (WR) event.

For NS recording, the volunteer laid down, with eyes open and at rest, for 3 minutes, without any stimulation. In WR, the volunteer laid down, and one word at a time was presented sequentially. Each word was shown for a period of 5 seconds, at the height of the volunteer's eyes, written in large fonts on a piece of cardboard, for a silent reading. After the reading, another 5 seconds of recording took place, in silence, before moving on to the next word. In total, the volunteer was asked to read ten words, namely: dog, football, shirt, soap opera, banana, tomato, music, cell 
phone, fabric and work. This choice of words, although random, sought to use words that evoked memories and emotions associated with the daily life of a common Brazilian individual. Examples of filtered and unfiltered EEG signals in the time domain, collected from a volunteer for both situations studied here, are shown in figure 1.
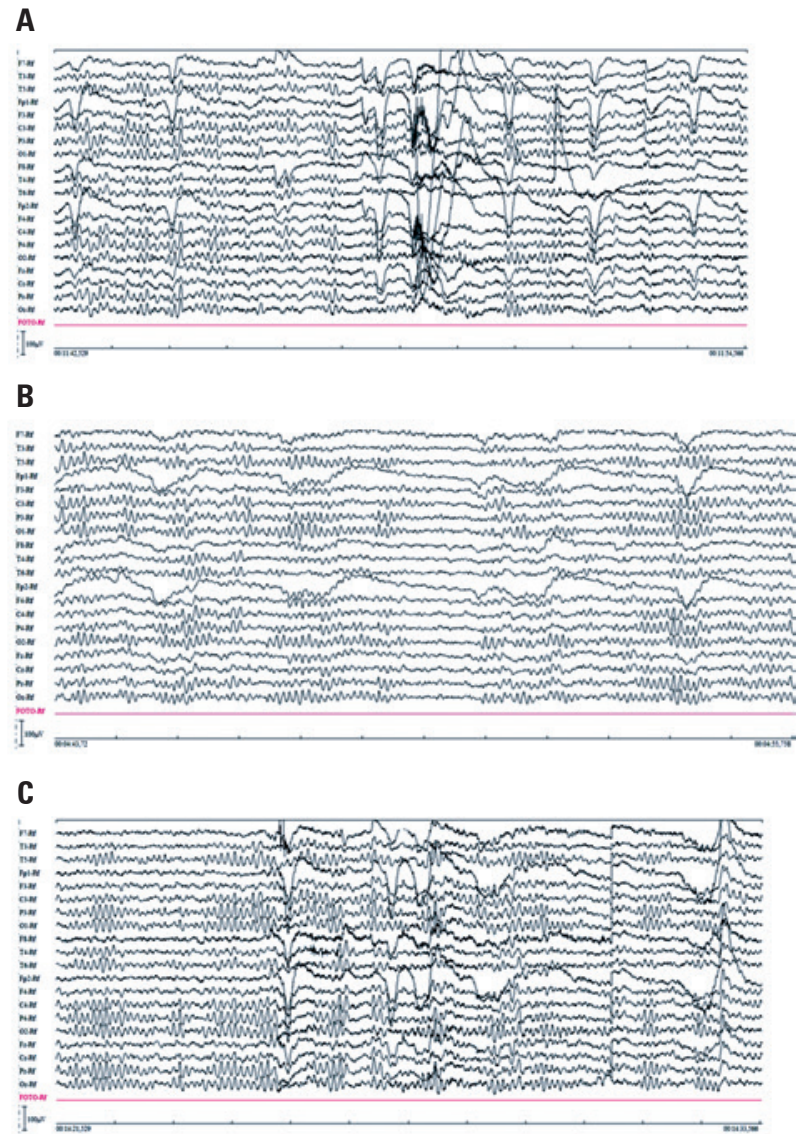

D

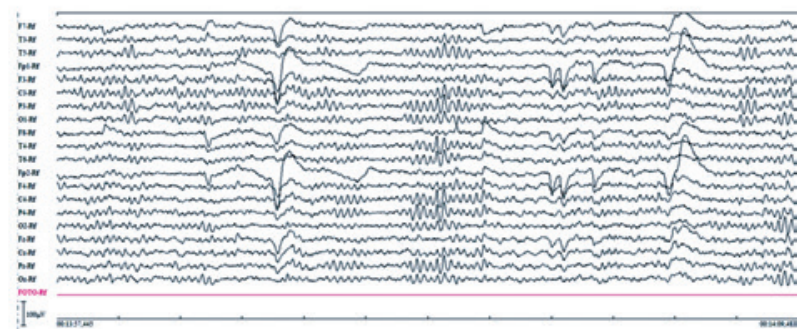

Figure 1. Examples of unfiltered and filtered electroencephalographic signals in the time domain collected from a volunteer. $(A)$ unfiltered signal of the no stimuli situation; (B) filtered signal of the no stimuli situation; (C) unfiltered signal of the word reading situation; (D) filtered signal of the word reading situation

\section{Pre-processing}

To ensure that the study considered a time interval during which the volunteer was actually performing the word reading act, the first and the last seconds recorded for each word read were excluded. Thus, for the WR event, ten 3-second epochs (stretches and segments) were analyzed, each epoch associated with the reading of a specific word. As for the NS event, each EEG recording was validated for separation into epochs of interest. The epochs, also lasting 3 seconds, were selected by a neurologist, who was a specialist in EEG analysis, through visualization. The morphology of a neurologically normal recording, devoid of visual artifacts, as expected for a healthy volunteer, was adopted as pattern.

We relied on filtering methods and visual analysis to avoid artifacts, such as $60 \mathrm{~Hz}$ noise, muscle artifacts, blinks, or others, to assure that the analyzed signal was related to the EEG tracing.

\section{Quantification of the brain signal}

The first tool used to quantify the signal was the discrete time Fourier transform (DTFT), whose calculation results in the spectral density (power) of the signal distributed at each frequency analyzed. The DTFT calculation is defined as shown in equation 1 .

$$
F(\omega)=\int_{-\infty}^{\infty} f(t) e^{-i \omega t} d t \text { (Equation 1) }
$$

where $F(\omega)$ is the DTFT of $f(t)$.

The normalized power percentage (NPP) quantifier measures the amount of signal power, covering all existing rhythms between 1 and $100 \mathrm{~Hz}$ (delta, theta, alpha, beta, gamma and high-gamma). The power contribution percentage (PCP) quantifier measures the power of each brain rhythm relatively to the total power of the spectrum, informing the contribution of each rhythm in the evaluated epoch. The input data for both quantifiers were ten epochs of the NS event, and ten epochs of the WR event.

Initially, for both NPP and PCP, the power spectral density $S_{x}$, was calculated using the DTFT. ${ }^{(15-17)}$ With the result of the calculation $S_{x}$, for all epochs of the NS and WR events, the values of NPP (equation 2), and the values of PCP were calculated (equation 3$).{ }^{(18)}$ The NPP quantifier is defined as in equation 2. 


$$
P P N_{x_{a}}(f, b)=\frac{s_{x} a(f, b)}{\operatorname{Max}\left(S_{x} a\right)}(\text { Equation } 2)
$$

Where $S_{x} a(f, b)$ is the power spectral density of the EEG signal at the $\mathrm{X}$ electrode, for event $a$ (NS or WR); where $b$ and $f$ correspond, respectively, to the corresponding epoch and the frequency value. $\mathrm{S}_{\mathrm{x}} \mathrm{a}$ is the power spectral density matrix, in which the lines represent the frequency values (f), and the columns refer to the epochs (b) $[\mathrm{W} / \mathrm{Hz}]$. $\operatorname{Max}\left(\mathrm{S}_{\mathrm{x}} \mathrm{a}\right)$ is the maximum amplitude, calculated after analyzing all elements of the $\mathrm{S}_{\mathrm{x}}$ a matrix $[\mathrm{W} / \mathrm{Hz}]$.

In this way, the calculation of the PCP quantifier is made according to equation 3 :

$$
P C P_{\text {rhythm }} i=\frac{\int_{f=f_{\text {in }} \text { rhythm }}^{f_{\text {out }} \text { rhythm }} \mid S_{\left.x_{i} i_{a}(f)\right|^{2} d f}}{P_{i_{a}}}(\text { Equation 3) }
$$

Where the index $i$ is associated with the epochs; index $a$, with the event (NS or WR); $f_{\text {in }}$ rhythm is the first frequency value of the analyzed rhythm $[\mathrm{Hz}] ; f_{\text {out }}$ rhythm is the last frequency value of the analyzed rhythm $[\mathrm{Hz}]$; $P i_{a}$ is the power calculated across the spectrum [W], whereas $a$ is the event.

The input data for the coherence quantifier were the same as for NPP and PCP (selected epochs of each event). Coherence is a statistical measure related to the degree of coupling of the frequency spectra, and its value depends on the correlations between the events in the frequency domain. Additional diagnostic information can also be provided by measuring the pairs of neocortical regions. ${ }^{(18-20)}$ This refers to the degree of phase similarity between two signals. ${ }^{(21)}$ The coherence calculation is done by the square magnitude of the cross spectral density of the two signals, as seen in equation 4.

$$
\left|\Gamma_{x y}\left(e^{j w}\right)\right|_{b}^{2}=\frac{\left|S_{x y}\left(e^{j w}\right)\right|^{2}}{S_{x}\left(e^{j w}\right) S_{y}\left(e^{j w}\right)}(\text { Equation 4) }
$$

I $b$ is the epoch considered; $\mathrm{S}_{\mathrm{xy}}$, the cross power spectral density $[\mathrm{W} / \mathrm{Hz}] ; \mathrm{S}_{\mathrm{x}}$, the spectral density of the $\mathrm{X}$ electrode; and $\mathrm{S}_{\mathrm{y}}$, the spectral density of the $\mathrm{U}$ electrode.

Results of equation 3 vary from zero to one, and values close to zero indicate a low correlation, and values close to one indicate a high correlation. This property is expressed by equation 5 .

$$
0 \leq\left|\Gamma_{x y}\left(e^{j w}\right)\right|^{2} \leq 1(\text { Equation } 5)
$$

To perform the coherence calculations, the electrode pairs F3-F4, C3-C4, P3-P4 and O1-O2 were taken into consideration, in the spectral range from 1 to $100 \mathrm{~Hz}$, from the delta rhythm to the high-gamma rhythm.

\section{Statistical analysis}

Since the NPP values varied over a wide range of frequency bands (1 to $100 \mathrm{~Hz}$ ), it was decided to divide these data into three bands: clinical rhythms (ranging between 1 and $30 \mathrm{~Hz}$ ); gamma rhythm (from 30 to $80 \mathrm{~Hz}$ ); and high-gamma rhythm (from 80 to $100 \mathrm{~Hz}$ ). From the NPP values per band, the NS and WR events were arranged in that order, so that time-frequency diagrams could be drawn up. These values were arranged in chronological order of events and by frequency, from the lowest to the highest values (considering each band separately). For each electrode analyzed, three time-frequency diagrams were generated: clinical rhythms, gamma rhythm, and high-gamma rhythm.

In order to verify the hypothesis of equality of NPP data in both events (NS and WR), the Mann-Whitney test was used, with $95 \%$ confidence interval. This is a non-parametric test for comparing independent samples to verify whether there is a difference between them. ${ }^{(22)}$ The result shows the level of significance between the data, represented by the $\mathrm{p}$ value. When the $\mathrm{p}$ value is less than $5 \%$, the equality hypothesis is rejected, assuming that the compared data are different.

The PCP values obtained were assessed using descriptive calculation (median \pm median standard deviation) to summarize the information obtained from each brain rhythm. These values were also compared for the two events using the Mann-Whitney test with the same level of significance, and the results are shown in a table.

Finally, the coherence values obtained in both the NS and WR events were used to create time-frequency diagrams. The time axis was defined, as well as for NPP, by values measured in the chronological epochs, respecting the order of events, in seconds, and the frequency axis comprised values ranging from the lowest to the highest contribution within each rhythm, in $\mathrm{Hz}$. The statistical comparison between the coherence values measured in the NS event and those obtained in the WR event was also implemented using the Mann-Whitney test, with a 5\% significance level. 


\section{RESULTS}

Figure 2 shows non-normalized topographies with the mean values of PCP of all volunteers for all rhythms: clinical (delta to beta), gamma, and high-gamma, demonstrating how the distribution and variation of rhythms occur, during the resting situation and the word reading situation, throughout all scalp leads. Using nonnormalized topography, each rhythm has its own scale, which is constructed using the maximum and minimum average power of the specific rhythm.

Figure 3 shows the time-frequency diagrams of the NPP values. In each figure, the $\mathrm{Fz}, \mathrm{Cz}, \mathrm{Pz}$ and $\mathrm{Oz}$ electrodes are shown. Figure 3, from A to D, shows the clinical rhythms; from $\mathrm{E}$ to $\mathrm{H}$, shows the gamma rhythm; and from I to L, shows the high-gamma rhythm. In all comparisons between NS (1 to 30 seconds) and WR (30 to 60 seconds) using the MannWhitney statistical test, the $\mathrm{p}$ values were less than 0.05 , indicating a statistical difference between the NPP measured at rest and the NPP measured during the word reading situation.

Figure 3, from A to D, shows that, in the frequency range between 10 and $13 \mathrm{~Hz}$, which the alpha band was more evident, the discrepancy between the NS and WR events was noticeable. In figure 3 , from $\mathrm{E}$ to $\mathrm{H}$, showing the gamma rhythm, the highest NPP values were concentrated in the 30 to $52 \mathrm{~Hz}$ bands, not only visually, but quantitatively. These values decreased in the WR process ( $\mathrm{p}$ value $<0.05$ ). In figure 3 , from I to L, showing the high-gamma rhythm, there was a more evident separation between NS and WR in this frequency range, and also, as in the gamma rhythm, there was a decrease in the NPP values during the WR event.
The PCP values of each event, with their respective $\mathrm{p}$ values, for each brain rhythm, are shown in table 1 (delta to beta) and table 2 (gamma and high-gamma), for the $\mathrm{C} 3, \mathrm{Cz}, \mathrm{C} 4, \mathrm{P} 3, \mathrm{Pz}, \mathrm{P} 4, \mathrm{~T} 5, \mathrm{~T} 6, \mathrm{O} 1, \mathrm{Oz}$, and $\mathrm{O} 2$ electrodes.

In the PCP calculation, as to clinical rhythms, the delta rhythm showed an increase in power in all electrodes during WR, when compared to NS. On the other hand, both in alpha and beta rhythms, PCP values decreased in the word reading situation. The theta frequency band variation showed a different PCP behavior, according to the region measured. For example, in the $\mathrm{P}, \mathrm{O}$ and $\mathrm{T}$ regions, the $\mathrm{PCP}$ increased during the word reading situation, whereas in the other regions this index decreased. In gamma and highgamma rhythms, PCP values decreased in the word reading situation, except in the occipital and temporal region. The gamma and high-gamma rhythms, in terms of PCP, were sensitive to the brain region. In the parietal region, there was no differentiation between the PCP values measured at rest and during the word reading situation. This indicated that, for these rhythms, analyzing the electrodes in this region was not effective for EEG segmentation into resting and cognitive activity.

The analysis of the third EEG signal quantifier, i.e. coherence, indicated that both for the clinical rhythms (Figure 4) and the gamma and high-gamma rhythms (Figures 5 and 6, respectively), the coherence between the symmetrical pairs of the electrodes was higher during the word reading situation. The discrepancy between these values measured at rest and during word reading situation was markedly greater for faster rhythms, rendering these rhythms clinically important in the evaluation conducted by neurologists.
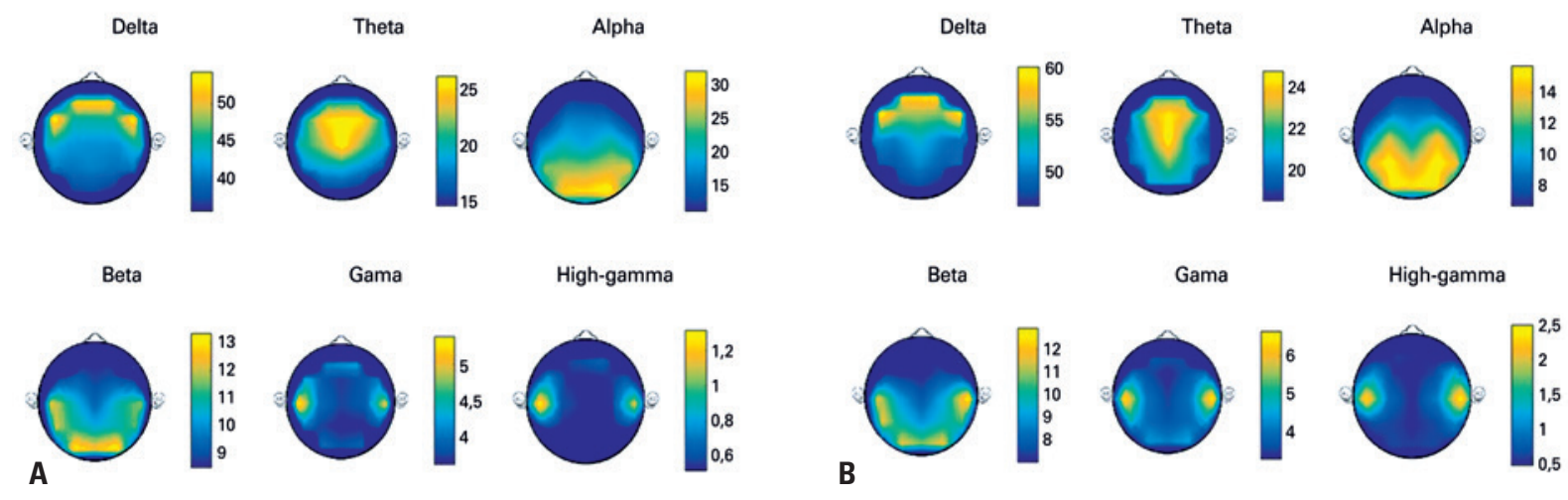

Figure 2. Topographies of the mean values of power contribution percentage of all volunteers. (A) topographies of clinical rhythms (delta to beta), gamma, and highgamma for the no stimulus situation; (B) topographies of clinical rhythms (delta to beta), gamma, and high-gamma for the word reading situation 

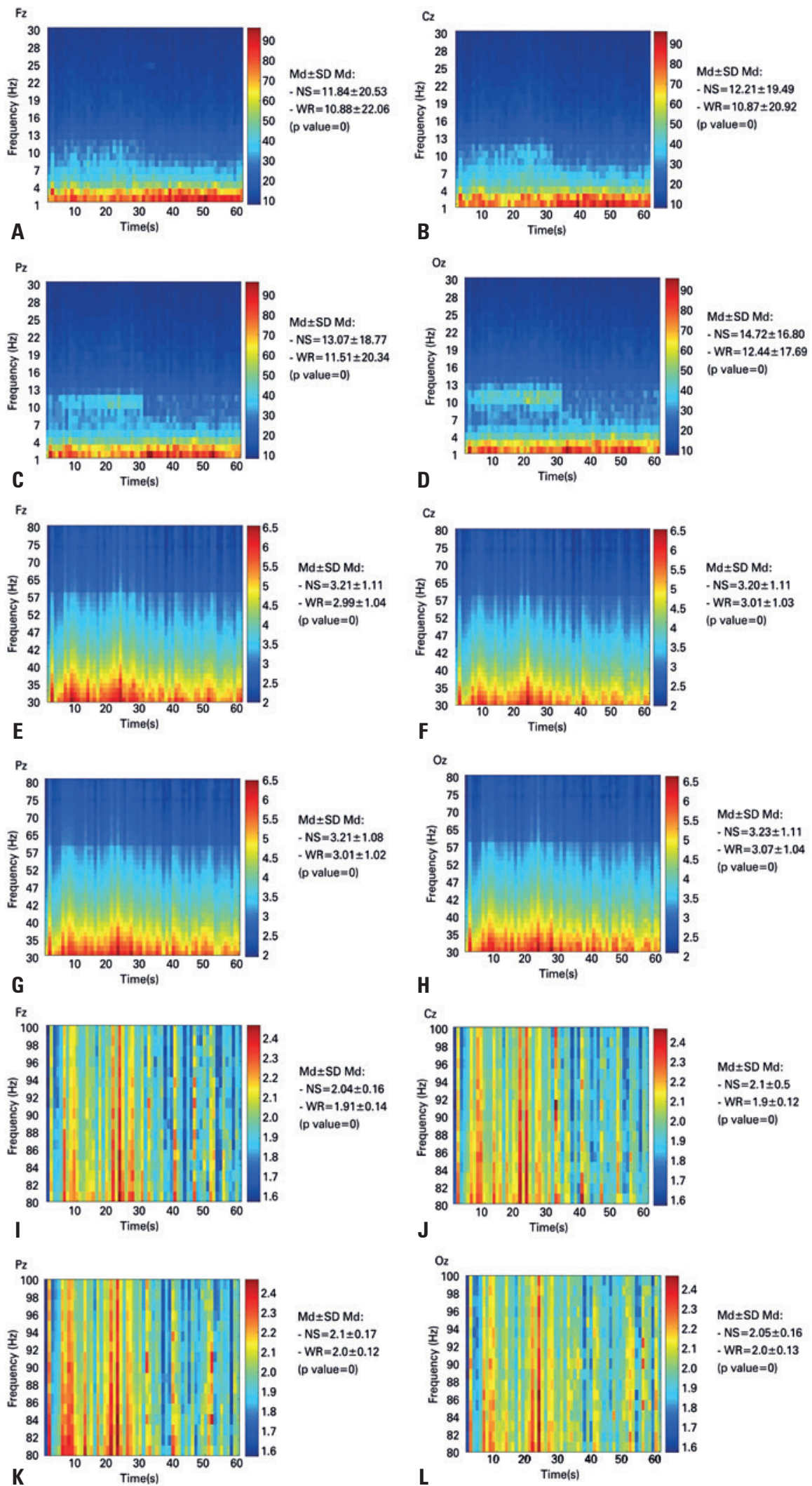

Md: Median; SD: standard deviation; NS: no stimuli; WR: word reading.

Figure 3. Time-frequency diagram of normalized power percentage for brain rhythms, with the first 30 seconds referring to the no stimulus event, and the last 30 seconds referring to the word reading event. $(A)$ diagram of the Fz electrode, clinical rhythms; $(B)$ diagram of the $\mathrm{Cz}$ electrode, clinical rhythms; $(\mathrm{C})$ diagram of the Pz electrode, clinical rhythms; (D) diagram of the $\mathrm{Oz}$ electrode, clinical rhythms; (E) diagram of the Fz electrode, gamma rhythm; (F) diagram of the $\mathrm{Cz}$ electrode, gamma rhythm; (G) diagram of the Pz electrode, gamma rhythm; (H) diagram of the Oz electrode, gamma rhythm; (I) diagram of the Fz electrode, high-gamma rhythm; (J) diagram of the $\mathrm{Cz}$ electrode, high-gamma rhythm; (K) diagram of the Pz electrode, high-gamma rhythm; (L) diagram of the $0 \mathrm{z}$ electrode, high-gamma rhythm 
Table 1. Percentage values of power contribution - clinical rhythms $(\alpha=5 \%)$

\begin{tabular}{|c|c|c|c|c|}
\hline Electrodes and situation & Delta & Theta & Alpha & Beta \\
\hline \multicolumn{5}{|l|}{ C3 } \\
\hline NS & 40.9 & 19.7 & 11.2 & 9.1 \\
\hline WR & 51.3 & 18.8 & 7.8 & 7.6 \\
\hline$p$ value & 0 & 0.6 & 0 & 0 \\
\hline \multicolumn{5}{|l|}{$\mathrm{CZ}$} \\
\hline NS & 40.8 & 23.3 & 11.4 & 8.2 \\
\hline WR & 53.3 & 22.4 & 7.5 & 6.6 \\
\hline$p$ value & 0 & 0.3 & 0 & 0 \\
\hline \multicolumn{5}{|l|}{ C4 } \\
\hline NS & 41.1 & 18.3 & 12.9 & 9.2 \\
\hline WR & 52.9 & 18.2 & 7.6 & 7.4 \\
\hline$p$ value & 0 & 0.8 & 0 & 0 \\
\hline \multicolumn{5}{|l|}{ P3 } \\
\hline NS & 40.7 & 18.3 & 13.1 & 9.3 \\
\hline WR & 49.9 & 18.3 & 8.7 & 8.2 \\
\hline$p$ value & 0 & 0 & 0 & 0 \\
\hline \multicolumn{5}{|l|}{$P Z$} \\
\hline NS & 41.5 & 16.0 & 13.2 & 9.1 \\
\hline WR & 52.6 & 19.7 & 8.5 & 7.8 \\
\hline$p$ value & 0 & 0 & 0 & 0 \\
\hline \multicolumn{5}{|l|}{ P4 } \\
\hline NS & 40.2 & 14.7 & 14.7 & 9.2 \\
\hline WR & 50.8 & 18.5 & 8.9 & 8.3 \\
\hline p value & 0 & 0 & 0 & 0 \\
\hline \multicolumn{5}{|l|}{ T5 } \\
\hline NS & 39.9 & 15.6 & 13.3 & 9.8 \\
\hline WR & 49.5 & 17.6 & 8.6 & 9.8 \\
\hline$p$ value & 0 & 0 & 0 & 0.5 \\
\hline \multicolumn{5}{|l|}{ T6 } \\
\hline NS & 39.9 & 13.2 & 14.4 & 9.6 \\
\hline WR & 51.3 & 17.0 & 8.4 & 9.1 \\
\hline$p$ value & 0 & 0 & 0 & 0 \\
\hline \multicolumn{5}{|l|}{01} \\
\hline NS & 35.7 & 12.4 & 15.3 & 11.1 \\
\hline WR & 47.9 & 18.4 & 9.6 & 9.9 \\
\hline$p$ value & 0 & 0 & 0 & 0 \\
\hline \multicolumn{5}{|l|}{$\mathrm{OZ}$} \\
\hline NS & 37.1 & 13.1 & 15.2 & 10.5 \\
\hline WR & 48.8 & 17.9 & 9.9 & 9.6 \\
\hline$p$ value & 0 & 0 & 0 & 0 \\
\hline \multicolumn{5}{|l|}{02} \\
\hline NS & 35.3 & 10.9 & 18.2 & 11.0 \\
\hline WR & 47.8 & 18.1 & 10.4 & 10.1 \\
\hline$p$ value & 0 & 0 & 0 & 0 \\
\hline
\end{tabular}

$p \geq 0.05$ indicates statistical equality.

NS: no stimulus; WR: word reading.
Table 2. Percentage values of power contribution - faster rhythms $(\alpha=5 \%)$

\begin{tabular}{lcc}
\hline Electrodes and situation & Gamma & High-gamma \\
\hline C3 & 3.8 & 0.5 \\
NS & 3.5 & 0.4 \\
WR & 0 & 0 \\
p value & & \\
CZ & 3.5 & 0.4 \\
NS & 3.1 & 0.4 \\
WR & 0 & 0 \\
P value & & \\
C4 & 3.7 & 0.5 \\
NS & 3.0 & 0.4 \\
WR & 0 & 0.1 \\
P value & & 0.5 \\
P3 & 3.6 & 0.5 \\
NS & 0.7 & 0.5 \\
WR & & \\
p value & 3.6 & \\
\hline
\end{tabular}

\section{PZ}

$\begin{array}{lll}\text { NS } & 3.5 & 0.4\end{array}$

$\begin{array}{lll}\text { WR } & 3.3 & 0.4\end{array}$

$\begin{array}{lll}p \text { value } & 0.1 & 0.1\end{array}$

P4

$\begin{array}{lll}\text { NS } & 3.5 & 0.5\end{array}$

$\begin{array}{lll}\text { WR } & 3.7 & 0.5\end{array}$

$\begin{array}{lll}p \text { value } & 0.1 & 0.3\end{array}$

T5

$\begin{array}{lll}\text { NS } & 3.8 & 0.5\end{array}$

$\begin{array}{lll}\text { WR } & 4.3 & 0.5\end{array}$

p value 00

T6

$\begin{array}{lll}\text { NS } & 3.6 & 0.5\end{array}$

$\begin{array}{lll}\text { WR } & 4.1 & 0.5\end{array}$

p value $\quad 0 \quad 0$

01

NS $\quad 3.7 \quad 0.5$

$\begin{array}{lll}\text { WR } & 4.1 & 0.5\end{array}$

$p$ value 0

$\mathrm{OZ}$

$\begin{array}{lll}\text { NS } & 3.6 & 0.5\end{array}$

$\begin{array}{lll}\text { WR } & 3.9 & 0.5\end{array}$

p value 00

02

$\begin{array}{lll}\text { NS } & 3.7 & 0.5\end{array}$

$\begin{array}{lll}\text { WR } & 4.1 & 0.5\end{array}$

$p$ value $\quad 0$

$p \geq 0.05$ : indicates statistical equality.

NS: no stimulus; WR: word reading. 


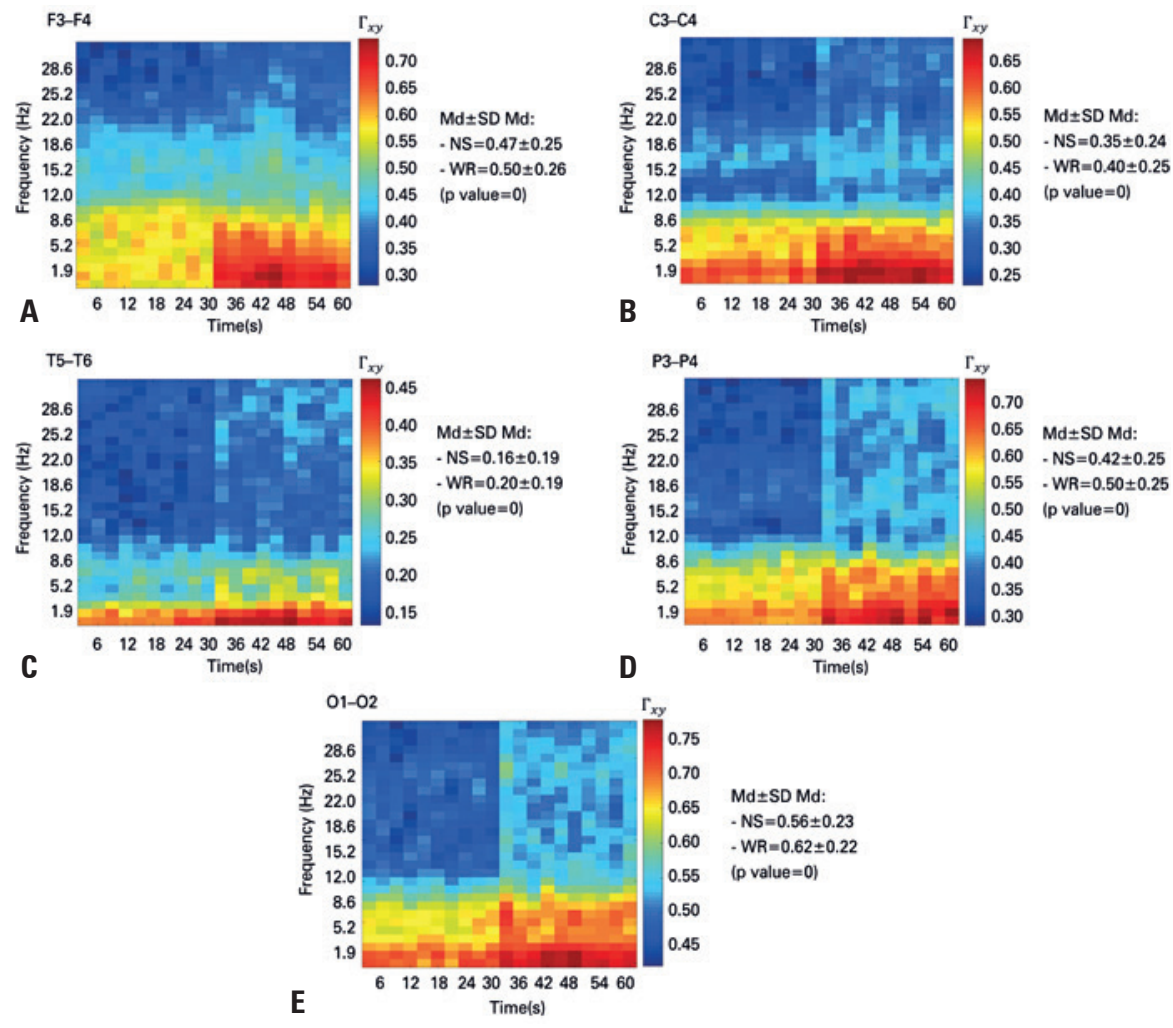

Md: median; SD: standard deviation; NS: no stimulus; WR: word reading.

Figure 4. Time-frequency coherence diagram for clinical rhythms, with the first 30 seconds referring to the no stimulus event, and the last 30 seconds referring to the word reading event. (A) diagram of the Fz electrode; (B) diagram of the $\mathrm{Cz}$ electrode; (C) diagram of the Pz electrode; (D) diagram of the $\mathrm{Oz}$ electrode
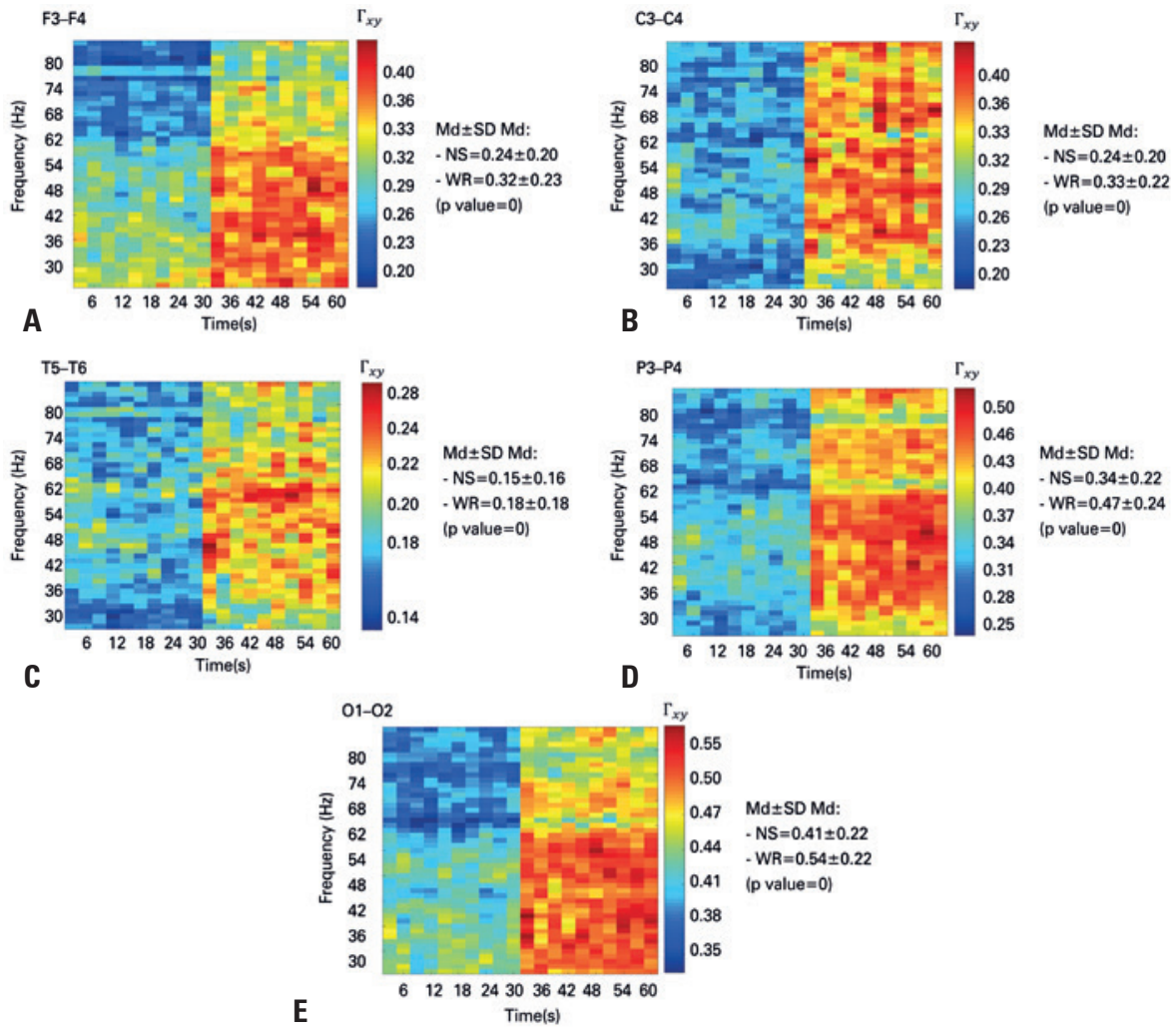

Md: median; SD: standard deviation; NS: no stimulus; WR: word reading.

Figure 5. Time-frequency coherence diagram for gamma band, with the first 30 seconds referring to the no stimulus event, and the last 30 seconds referring to the word reading event. (A) diagram of the Fz electrode; (B) diagram of the Cz electrode; (C) diagram of the Pz electrode; (D) diagram of the Oz electrode 

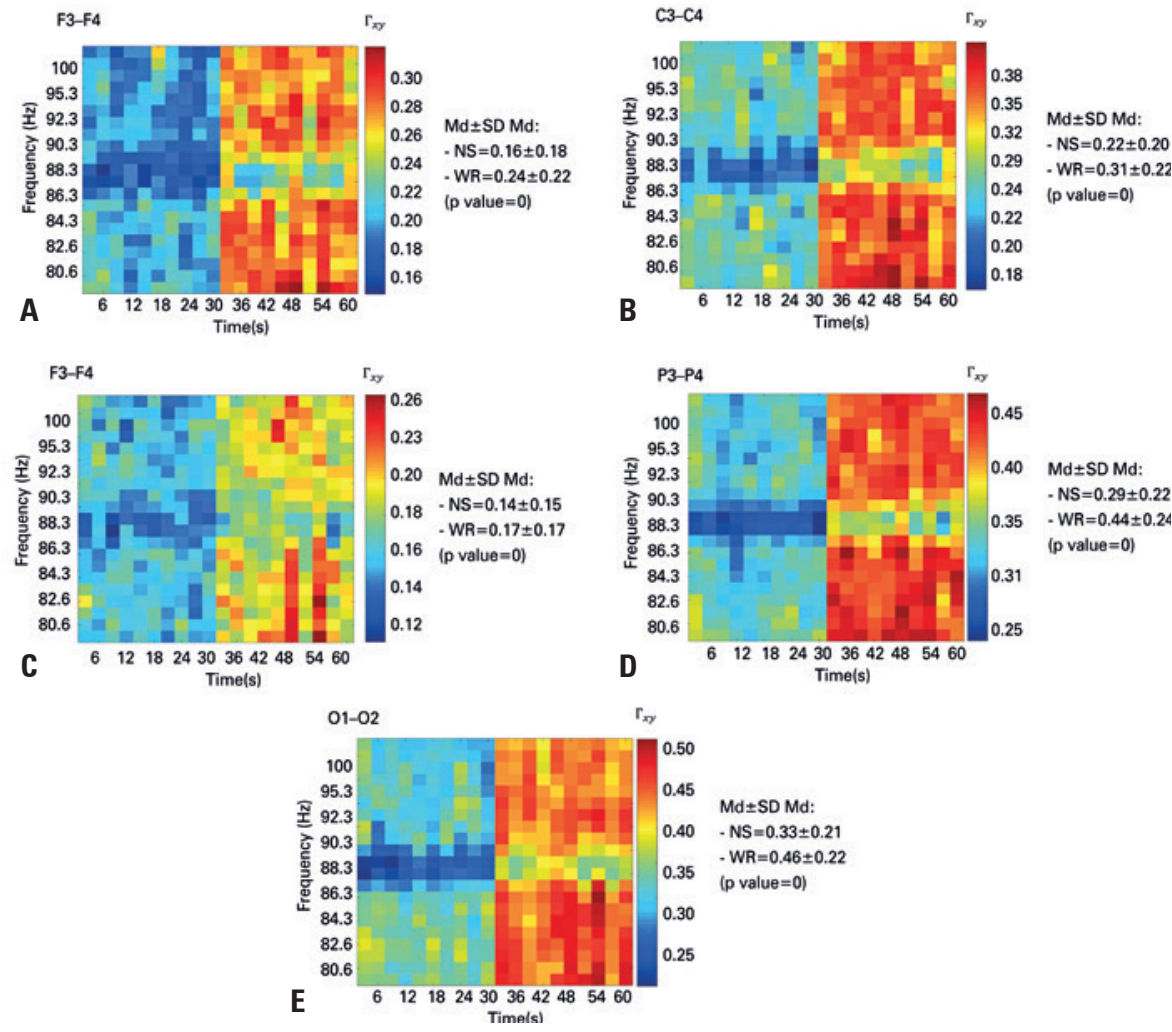

Md: median; SD: standard deviation; NS: no stimulus; WR: word reading.

Figure 6. Time-frequency coherence diagram for high-gamma band, with the first 30 seconds referring to the no stimulus event, and the last 30 seconds referring to the word reading event. (A) diagram of the Fz electrode; (B) diagram of the $\mathrm{Cz}$ electrode; (C) diagram of the Pz electrode; (D) diagram of the $\mathrm{Oz}$ electrode

\section{DISCUSSION}

The review by Antonenko et al., ${ }^{(23)}$ describes two case studies: one on the cognitive load in hypertext reading, with 20 students, and the other on the cognitive load in multimedia reading, with 38 students. The results of the first case showed a significant decrease in alpha power during the 20 seconds of reading and, in the second case, this reduction was also noticed in the frontal region of the brain.

In the study by von Stein et al., ${ }^{(20)}$ with 19 volunteers, coherence was analyzed in three different modalities: written word, auditory presentation and visual presentation of the object. Each stimulus lasted 2 seconds, with an interval of 2 to 3 seconds between all conditions. For comparison, a resting state was used with the volunteer relaxed and with eyes open. During reading, the gamma coherences between the parietal and temporal cortex increased. In addition, alpha coherence also demonstrated an increase in temporal electrodes.

The study by Bedo et al., ${ }^{(24)}$ analyzing independent components, showed that, both in the ventral occipitotemporal cortex and in the central cortex, progression of theta band and gamma band synchronization occurs, and the information flow from these bands are associated with the visual and language processing areas.

The study, ${ }^{(25)}$ carried out with two male volunteers, evaluated guitar score reading, involving an unpublished sequence of musical notes, previously developed for the experiment. The results obtained revealed changes in the theta to gamma bands during cognitive activities. Our study shows changes in the four brain rhythms during reading activities.

In a review by Klimesch, ${ }^{(26)}$ alpha activity is suppressed in the word reading situation, which was also evidenced in our present study.

In the research by Fitzgibbon et al., ${ }^{(27)}$ an analysis implemented in 20 adults showed that, during cognitive tasks, including reading, the powers of the gamma and theta bands increased, respectively, by two to five, and one to three times, when compared to resting.

The study by Kornrumpf et al., ${ }^{(28)}$ aimed to investigate the spatial distribution of attention during reading, analyzing alpha band oscillations in the EEG. In their findings, it was concluded that, during reading, 
there is a right lateralization of posterior alpha activity, which is directly linked to attention, and is also related to oculomotor behavior in reading.

The study by Bizas et al., ${ }^{(4)}$ evaluated the EEG of 17 neurologically healthy, adult and right-handed volunteers, during the execution of several cognitive processes, involving reading. EEG records were quantified using energy spectrum measurements in the four frequency bands (delta to beta). The results led to the conclusion that the left cerebral hemisphere showed greater spectral variations in the word reading situation. In contrast, our study showed greater PCP variation in the right hemisphere for the parietal and occipital regions. In the other regions, the variations in both hemispheres were similar.

\section{CONCLUSION}

This article is essentially focused on the reading activity and, therefore, the results characterize this pure cognitive process, avoiding several types of simultaneous stimuli and allowing the quantitative results to be associated specifically with the physiology of reading, based on the electroencephalographic signal.

Most of the results obtained in this research are in agreement with the literature. Particularly considering the faster, gamma $(30-80 \mathrm{~Hz})$ and high-gamma $(80-100 \mathrm{~Hz})$ rhythms, the changes in the power contribution percentage values in the temporal and occipital regions during the word reading situation, compared to the frontal and central regions, increased reasonably. The quantitative data obtained represent a proposal for a "normal" quantitative pattern associated with the pure reading process, in view of the high number of individuals evaluated. Therefore, these results can be useful both in the assessment of clinical neurological conditions (patients in a coma) and for brain-machine interface applications (patients/individuals with hearing/ verbalization problems). For a patient in an open-eyed coma-like state, unable to communicate verbally, if brain changes similar to those found in this study are observed, this could be an indication that the patient can read. This may be an alternative communication channel between the patient and the medical team/ family. However, it is impossible to affirm that the same changes found in a "normal" neurological situation are present in a neurological condition with any form of brain dysfunction. These perspectives represent possible future studies, as a result of this article.

\section{॥ ACKNOWLEDGEMENTS}

To the financing agencies, for structural support for research: Coordenação de Aperfeiçoamento de Pessoal de Nivel Superior (CAPES), The Fundação de Amparo à Pesquisa do Estado de Minas Gerais (FAPEMIG) and the Conselho Nacional de Desenvolvimento Cientifico e Tecnológico (CNPq). Special thanks to the neurology team from Hospital de Clínicas da Universidade Federal de Uberlândia (UFU), for the technical neurological consultancy and recording equipment, and to several Research Mentorship students, for the support during the recording works.

\section{AUTHORS' INFORMATION}

Ramos CD: http://orcid.org/0000-0002-7864-5568

Lima IN: http://orcid.org/0000-0002-5497-8923

Rodrigues AL: http://orcid.org/0000-0002-7052-1368

Magalhães KA: http://orcid.org/0000-0002-9405-1049

Rodrigues AA: http://orcid.org/0000-0002-9687-2158

Destro-Filho JB: http://orcid.org/0000-0001-5306-8058

\section{REFERENCES}

1. Smith F. Understanding reading. 6th ed. United Kingdom: Routledge; 2004. p. $1-5$.

2. Dehaene S. Les Neurones de la lecture. Paris: Odile Jacob; 2007. p. 321-5

3. Bolger DJ, Perfetti CA, Schneider W. Cross-cultural effect on the brain revisited: universal structures plus writing system variation. Hum Brain Mapp. 2005;25(1):92-104.

4. Bizas E, Simos PG, Stam CJ, Arvanitis S, Terzakis D, Micheloyannis S. EEG correlates of cerebral engagement in reading tasks. Brain Topogr. 1999; 12(2):99-105.

5. Dehaene S, Cohen L. Cultural recycling of cortical maps. Neuron. 2007; 56(2):384-98. Review.

6. McCandliss BD, Cohen L, Dehaene S. The visual word form area: expertise for reading in the fusiform gyrus. Trends Cogn Sci. 2003;7(7):293-9.

7. Mostow J, Chang KM, Nelson J. Toward exploiting EEG input in a reading tutor. In: Biswas G, Bull S, Kay J, Mitrovic A, editors. Artificial intelligence in education. 15th International Conference, AIED 2011, Auckland, New Zealand, June 28 - July 2, 2011, Proceedings. Berlin: Springer-Verlag Berlin Heidelberg; 2011. p. 230-7. [Serie Lecture Notes in Artificial Intelligence, 6738] [Internet]. [cited 2019 0ct 6]. Available from: https://citeseerx.ist.psu. edu/viewdoc/download?doi=10.1.1.228.5174\&rep = rep1\&type $=$ pdf

8. Taylor MJ, Baldeweg T. Application of EEG, ERP and intracranial recordings to the investigation of cognitive functions in children. Dev Sci. 2002;5(3): 318-34.

9. Olejniczak P. Neurophysiologic basis of EEG. J Clin Neurophysiol. 2006; 23(3):186-9. Review.

10. Schomer DL, Silva FH. Niedermeyer's electroencephalography: basic principles, clinical applications, and related fields. 6th ed. USA: Lippincott Williams \& Wilkins; 2010. p. 153-239

11. Freeman W, Quiroga RO. Imaging brain function with EEG. New York: SpringerVerlag; 2013. p. 5-47 
12. Teplan M. Fundamentals of EEG measurement. Meas Sci Rev. 2002; 2(2):1-11.

13. Buzsáki G. Rhythms of the brain. Oxford University Press; 2006. p. 29-231.

14. Kucewicz MT, Berry BM, Kremen V, Brinkmann BH, Sperling MR, Jobst BC, et al. Dissecting gamma frequency activity during human memory processing. Brain. 2017;140(5):1337-50.

15. Ramos CD. Caracterização do eletroencefalograma normal em situação de vigília: elaboração da base de dados e análise quantitativa [tese] [Internet]. Uberlândia: Universidade Federal de Uberlândia; 2017 [citado 2020 Out 2]. Disponível em: https://repositorio.ufu.br/handle/123456789/19571

16. Sörnmo L, Laguna P. Bioelectrical signal processing in cardiac and neurological applications. Cambridge: Academic Press; 2005. p. 55-8.

17. Kannathal N, Choo ML, Acharya UR, Sadasivan PK. Entropies for detection of epilepsy in EEG. Comput Methods Programs Biomed. 2005;80(3):187-94. Erratum in: Comput Methods Programs Biomed. 2006;81(2):193.

18. Ramos CD, Pereira GM, Rodrigues AA, Campos M, Destro Filho JB, Carrijo GA. Quantitative analysis of EEG records in distinct states of consciousness: a case study on Brazilian patient. IIEE Lat Am Trans. 2018;16(7):1878-83.

19. Cavinato M, Genna C, Manganotti P, Formaggio E, Storti SF, Campostrini S, et al. Coherence and consciousness: study of fronto-parietal gamma synchrony in patients with disorders of consciousness. Brain Topogr. 2015;28(4):570-9.
20. von Stein A, Sarnthein J. Different frequencies for different scales of cortical integration: from local gamma to long range alpha/theta synchronization. Int J Psychophysiol. 2000;38(3):301-13. Review.

21. Scharinger $C$, Kammerer $Y$, Gerjets P. Pupil dilation and EEG alpha frequency band power reveal load on executive functions for link-selection processes during text reading. Plos One. 2015;10(6):E0130608.

22. Vincent WJ, Weir JP. Statistics in kinesiology. 4th ed. Champaign: Human Kinetics; 2012. p. 233-6.

23. Antonenko P, Paas F, Grabner R, van Gog T. Using electroencephalography to measure cognitive load. Educ Psychol Rev. 2010;22:425-38.

24. Bedo N, Ribary U, Ward LM. Fast dynamics of cortical functional and effective connectivity during word reading. Plos One. 2014;9(2):e88940.

25. Bonini-Rocha AC, Chiaramonte M, Zaro MA, Timm MI, Wolff D. Observação das evidências cognitivas de aprendizagem motora no desempenho de jovens violonistas monitoradas por eletroencefalograma: um estudo piloto. Ciênc Cogn. 2009;14(1):103-20.

26. Klimesch W. EEG alpha and theta oscillations reflect cognitive and memory performance: a review and analysis. Brain Res Brain Res Rev. 1999;29(2-3): 169-95. Review.

27. Fitzgibbon SP, Pope KJ, Mackenzie L, Clark CR, Willoughby JO. Cognitive tasks augment gamma EEG power. Clin Neurophysiol. 2004;115(8):1802-9.

28. Kornrumpf B, Dimigen 0, Sommer W. Lateralization of posterior alpha EEG reflects the distribution of spatial attention during saccadic reading Psychophysiology. 2017;54(6):809-23. 